\title{
DARK MATTER IN THE UNIVERSE
}

Edited by J. KORMENDY and G. R. KNAPP

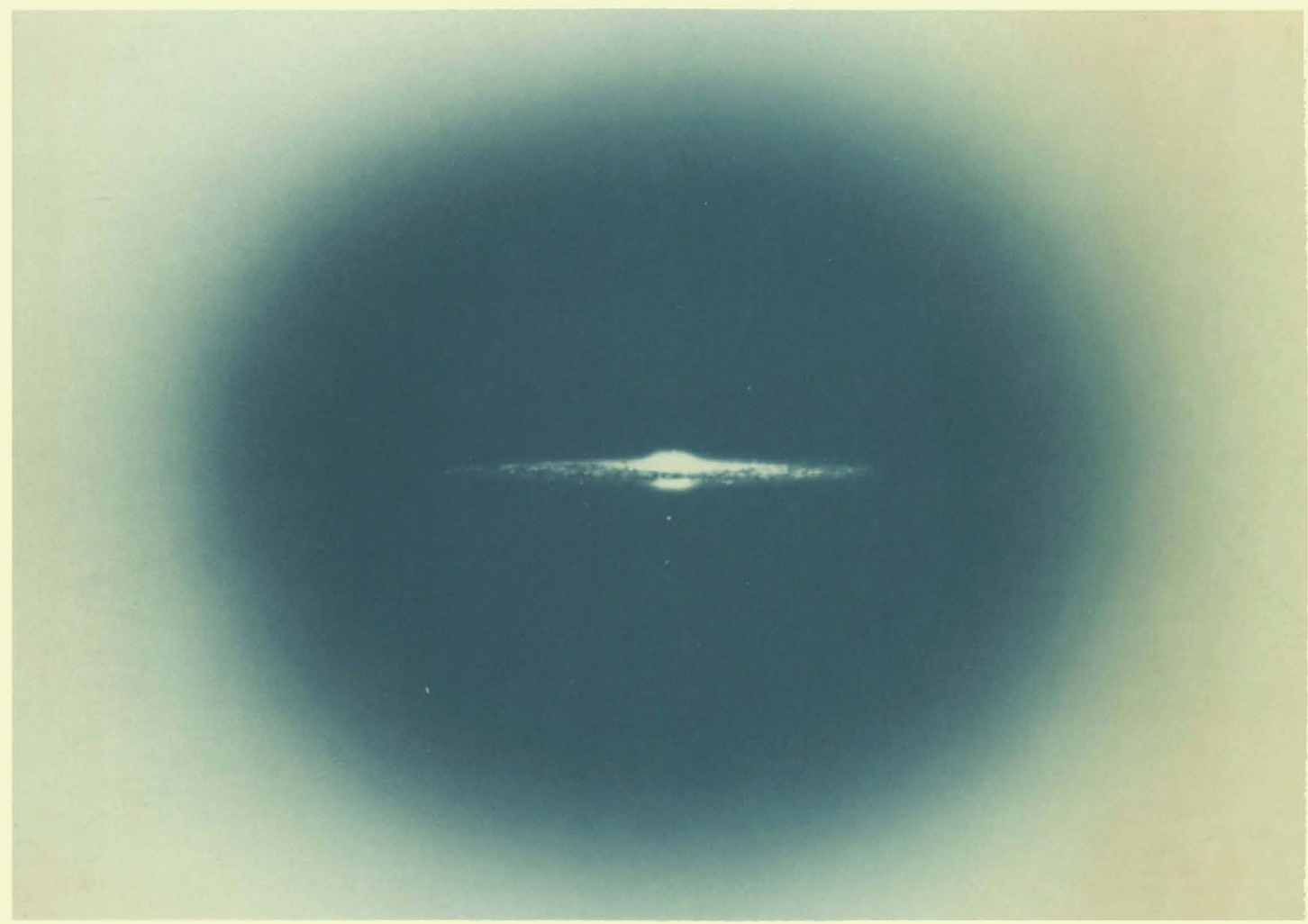

D. REIDEL PUBLISHING COMPANY 
DARK MATTER IN THE UNIVERSE 


\title{
DARK MATTER IN THE UNIVERSE
}

PROCEEDINGS OF THE 117TH SYMPOSIUM OF THE INTERNATIONAL ASTRONOMICAL UNION HELD IN PRINCETON, NEW JERSEY, U.S.A., JUNE 24-28, 1985

\author{
EDITED BY \\ J. KORMENDY \\ Dominion Astrophysical Observatory, Herzberg Institute of Astrophysics, \\ Victoria, B.C., Canada \\ and \\ G. R. KNAPP \\ Department of Astrophysical Sciences, Princeton University, \\ Princeton, New Jersey, U.S.A.
}

\footnotetext{
D. REIDEL PUBLISHING COMPANY

A MEMBER OF THE KLUWER ACADEMIC PUBLISHERS GROUP DORDRECHT / BOSTON / LANCASTER / TOKYO
}

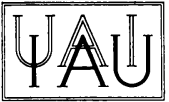


International Astronomical Union. Symposium

(117th: 1985: Princeton, N.J.)

Dark matter in the universe.

At head of title: International Astronomical Union = Union astronomique internationale.

Sponsored by IAU Commission 28 (Galaxies) et al.

Includes index.

1. Interstellar matter-Congresses. 2. Galaxies-Congresses. 3. Stars-Cong-

resses. I. Kormendy, J. (John) II. Knapp, G. R. III. International

Astronomical Union. IV. International Astronomical Union. Commission 28

(Galaxies) V. Title.

QB790.I573 $1985 \quad 523.1^{\prime} 12 \quad 86-21905$

ISBN 90-277-2356-7

ISBN 90-277-2357-5 (pbk.)

\author{
Published on behalf of \\ the International Astronomical Union \\ by \\ D. Reidel Publishing Company, P. O. Box 17, 3300 AA Dordrecht, Holland
}

All Rights Reserved

(C) 1987 by the International Astronomical Union

\author{
Sold and distributed in the U.S.A. and Canada \\ by Kluwer Academic Publishers, \\ 101 Philip Drive, Assinippi Park, Norwell, MA 02061, U.S.A. \\ In all other countries, sold and distributed \\ by Kluwer Academic Publishers Group, \\ P. O. Box 322, 3300 AH Dordrecht, Holland
}

No part of the material protected by this copyright notice may be reproduced or utilized in any form or by any means, electronic or mechanical, including photocopying, recording or by any information storage and retrieval system, without written permission from the publisher.

Printed in The Netherlands 
TABLE OF CONTENTS

FRONTISPIECE

POSTER PAPERS NOT SUBMITTED FOR THE PROCEEDINGS

ORGANIZING COMMITTEES

LIST OF PARTICIPANTS

* DARK MATTER: KEY ISSUES Sandra M. Faber 1

* DARK MATTER IN THE GALACTIC DISK John N. Bahcall 17

EXTREME M DWARFS AND BROWN DWARFS IN A DEEP CCD SURVEY

P. Chikotas Boeshaar, J. A. Tyson and P. Seitzer

KINEMATICS OF THE GALACTIC INNER SPHEROID

G. Gilmore and R. Wyse

RELATIVELY DARK MATTER: THE LOCAL MASS DENSITY OF STELLAR

REMNANTS Richard Green

THE DYNAMICS OF OPEN CLUSTERS Robert D. Mathieu

SEEN AND UNSEEN MATTER IN THE GALACTIC DISC

Annie Robin, Olivier Bienaymé and Michel Crézé

KINEMATICS OF NEARBY FV STARS

W. L. H. Shuter and W. N. Stocker

* THE LOCAL GALACTIC ESCAPE VELOCity

Bruce W. Carney and David W. Latham

* CONSTRAINTS ON THE DARK MATTER FROM OPTICAL ROTATION CURVES

Vera C. Rubin

DIFFERENCES IN MASS DISTRIBUTION FOR FIELD AND CLUSTER SPIRAL

GALAXIES David Burstein and Vera C. Rubin

* HI ROTATION CURVES OF GALAXIES

R. Sancisi and T. S. van Albada

( $*$ indicates review paper) 
KINEMATICS AND WARP IN NGC 4565

S. Casertano, R. Sancisi and T. S. van Albada

MASS/LUMINOSITY RATIOS FROM ROTATION OF HI IN SO GALAXIES

Wim van Driel and Hugo van Woerden

* MASS DETERMINATIONS AND DARK MATTER AT INTERMEDIATE SCALES

J. P. Ostriker

THE MASS OF THE BINARY GALAXIES NGC 4038/39 (THE "ANTENNAE")

J. M. Mahoney, B. F. Burke and J. M. van der Hulst

RADIAL VELOCITIES OF REMOTE GLOBULAR CLUSTERS

Ruth C. Peterson

THE TROUBLE WITH BINARY GALAXIES N. A. Sharp 96

* EVIDENCE FOR DARK MATTER IN GALACTIC SYSTEMS Marc Davis

GALAXY LUMINOSITY FUNCTIONS, M/L RATIOS, AND CLOSURE OF

THE UNIVERSE James E. Felten

ABOUT THE COMA CLUSTER (PROGRESS REPORT)

D. Gerbal, G. Mathez, A. Mazure and E. Salvadore-Solé

ESTIMATING THE MASSES OF GALAXY GROUPS: ALTERNATIVES TO THE

VIRIAL THEOREM J. Heisler, S. Tremaine and J. Bahcall

BIASES IN MASS ESTIMATES OF GROUPS OF GALAXIES

Gary A. Mamon

THE PECULIAR VELOCITY OF THE LOCAL GROUP IN THE DIRECTION OF

THE VIRGO CLUSTER L. Staveley-Smith and R. D. Davies

THE RING OF H I IN LEO: PROBING THE MASS DISTRIBUTION

IN A GALAXY GROUP

Stephen E. Schneider, Edwin E. Salpeter and Yervant Terzian

CLUSTERING ON A SCALE OF $10^{18} \mathrm{M}_{\odot} \quad \mathrm{R}$. Brent Tully

* PARAMETERS FOR DARK HALOS K. C. Freeman

HALO PARAMETERS OF SPIRAL GALAXIES

E. Athanassoula, A. Bosma and S. Papaioannou

DYNAMICAL INTERACTION BETWEEN THE DIFFERENT COMPONENTS OF SO-Sd GALAXIES R. Bacon and L. Martinet

IS THE RATIO OF DARK-TO-LUMINOUS MATTER A FUNCTION OF GALAXY MASS AND/OR LUMINOSITY? C. Carignan 
SOME REGULARITIES IN THE MISSING MASS PROBLEM

S. Casertano and J. N. Bahcall

MEASUREMENT OF DARK MATTER IN SPIRAL GALAXIES

Stephen M. Kent

MASS-TO-LIGHT RATIOS OF SPIRAL GALAXIES J. Patricia Vader

DARK MATTER IN DWARF GALAXIES John Kormendy

* THE SEARCH FOR DARK MATTER IN DRACO AND URSA MINOR:
A THREE YEAR PROGRESS REPORT
M. Aaronson and E. Olszewski

HI AND MASS DISTRIBUTION IN THE DWARF "REGULAR" GALAXY UGC 2259

C. Carignan, R. Sancisi and T. S. van Albada

NEUTRAL HYDROGEN OBSERVATIONS OF dI GALAXIES IN THE VIRGO

CLUSTER G. L. Hoffman, E. E. Salpeter and G. Helou

NEUTRINO MASS LIMITS AND DARK HALOS

Jes Madsen and Richard Epstein

* X-RAYS FROM GALAXIES AND CLUSTERS OF GALAXIES: OBSERVATIONS

AND PHENOMENOLOGY C. R. Canizares

* X-RAY HALOS IN GALAXIES AND CLUSTERS OF GALAXIES: THEORY

Craig L. Sarazin

* COOLING FLOWS AND THE FORMATION OF DARK MATTER

A. C. Fabian, K. A. Arnaud and P. A. Thomas

HOT CORONAE AROUND EARLY-TYPE GALAXIES: EVIDENCE FOR DARK HALOS

W. Forman, C. Jones and W. Tucker

EXTENDED X-RAY EMISSION FROM EARLY-TYPE GALAXIES: COMPARISON

WITH OPTICAL G. Trinchieri and G. Fabbiano

FILAMENTARY NEBULOSITY SURROUNDING M87

S. van den Bergh and C. J. Pritchet

* GRAVITATIONAL LENSES AND DARK MATTER: THEORY

J. Richard Gott, III

* GRAVITATIONAL LENSES AND DARK MATTER: OBSERVATIONS

Edwin L. Turner

A SEARCH FOR GRAVITATIONAL LENSING

J. N. Hewitt, G. I. Langston, J. H. Mahoney, B. F. Burke,

E. L. Turner, C. R. Lawrence and C. L. Bennett 
GALAXY MASS DISTRIBUTION FROM GALAXY-GALAXY GRAVITATIONAL

LENSING J. Anthony Tyson

* DARK MATTER: OBSERVATIONAL ASPECTS

Jaan Einasto, Mihkel Joeveer and Enn Saar

243

* N-BODY RESULTS ON DARK MATTER Simon D. M. White

263

ARE NUMERICAL SIMULATIONS RELIABLE? PROPOSED IMPROVEMENTS

AND TESTS F. R. Bouchet

COLD DARK MATTER: GALACTIC HALOS

C. S. Frenk

280

SIMULATIONS OF COMPACT GROUPS OF GALAXIES WITH HALOS

T. Ishizawa

281

VOIDS IN THE 2D CFA CATALOG

M. Lachieze-Rey and F. Bouchet

282

AN UPPER LIMIT ON THE MASSES OF GALAXIES IN CLUSTERS

David Merritt and Simon D. M. White

CLUSTERING PROPERTIES OF COLD DARK MATTER UNIVERSES AND THE

CFA REDSHIFT SURVEY: A UNIFORM COMPARISON

Richard Nolthenius and Simon White

FORMATION OF GALACTIC HALOS IN THE COLD DARK MATTER UNIVERSE:

COMPUTER SIMULATIONS

P. J. Quinn, J. K. Salmon and W. H. Zurek

FORMATION OF LARGE SCALE STRUCTURE IN THE EXPLOSION SCENARIO

S. Saarinen, A. Dekel and B. J. Carr

PROFILES OF GALAXY CLUSTERS IN COSMOLOGICAL SCENARIOS

Michael J. West, Avishai Dekel and Augustus Oemler, Jr.

* HALOS AND DISK STABILITY Agris J. Kalnajs

MASSIVE HALOS AND THE STABILITY OF HOT STELLAR DISCS

E. Athanassoula and J.A. Sellwood

THE GLOBAL STABILITY OF OUR GALAXY J. A. Sellwood

301

* OBSERVABLE CONSEqUENCES OF TRIAXIAL halOS James Binney

303

SELF-GRAVITATING POLAR RING MODELS Linda S. Sparke

DISTRIBUTION OF DARK MATTER IN POLAR RING GALAXIES

Bradley C. Whitmore, Douglas B. McElroy,

François Schweizer and Vera C. Rubin 
HALOS AROUND ELLIPTICALS AND THE ENVIRONMENT DEPENDENCE OF HUBBLE TYPE W. H. Zurek, P. J. Quinn and J. K. Salmon

* THE MODIFIED NEWTONIAN DYNAMICS AS AN ALTERNATIVE TO HIDDEN MATTER Mordehai Milgrom and Jacob Bekenstein

GRAVITATIONAL CHANNELS AND THE COSMOLOGICAL CONSTANT $\Lambda$ T. Ishizawa

* GALAXY FORMATION Joseph Silk

GALAXY FORMATION IN A UNIVERSE DOMINATED BY COLD DARK MATTER Edmund Bertschinger

EMBEDDING OF GALACTIC SYSTEMS IN EXTENDED NEUTRINO CLOUDS R. Cowsik and P. Ghosh

DWARF GALAXIES, COLD DARK MATTER, AND BIASED GALAXY FORMATION Avishai Dekel and Joseph Silk

HIERARCHICAL CLUSTERING: ANGULAR MOMENTUM DENSITY ANTI-CORRELATION Yehuda Hof fman

THE FORMATION OF GALACTIC HALOS IN UNIVERSES DOMINATED BY COLD DARK MATTER Barbara S. Ryden and James E. Gunn

HYDROGEN MOLECULES AND THE RADIATIVE COOLING OF PREGALACTIC SHOCKS Paul R. Shapiro and Hyesung Kang

COSMOLOGICAL HII REGIONS

Paul R. Shapiro, Ira Wasserman and Mark L. Giroux

A MODEL FOR THE SEQUENCE OF ELLIPTICAL GALAXIES

Rosemary F. G. Wyse and Bernard J. T. Jones

* NON-LINEAR EVOLUTION OF INHOMOGENEITIES IN UNIVERSES DOMINATED BY DARK MATTER S. F. Shandarin (read by A. Szalay)

* ANISOTROPY OF THE MICROWAVE BACKGROUND AND COSMOLOGICAL DARK MATTER V. N. Lukash

DISTURBANCE OF THE CBR BY ISOTHERMAL PERTURBATIONS

Hideo Kodama, Yasushi Suto and Katsuhiko Sato

* POSSIBLE CONSTITUENTS OF halOS Martin J. Rees

LIMITS ON THE MISSING MASS IN DARK STELLAR REMNANTS Janet E. Jones, Philip Mellor and Jesper Storm 
MASSIVE BLACK HOLES IN GALACTIC HALOS?

C. G. Lacey and J. P. Ostriker

BIMODAL STAR FORMATION AND REMNANT-DOMINATED GALACTIC MODELS

Richard B. Larson

BACKGROUND LIGHT FROM POPULATION III STARS

Jonathan C. McDowell

414

* OBSERVATIONAL SEARCHES FOR DARK HALOS P. C. van der Kruit

FAINT PHOTOMETRY OF EDGE-ON SPIRAL GALAXIES: A SEARCH FOR MASSIVE HALOS

Michael F. Skrutskie, Mark A. Shure and Steven Beckwith

* AN INFRARED SEARCH FOR SUBSTELLAR OBJECTS F. J. Low

* CONTRIBUTIONS TO THE LOCAL GRAVITATIONAL FIELD FROM BEyOND THE LOCAL SUPERCLUSTER A. Yahil

* A COSMOLOGIST'S TOUR THROUGH THE NEW PARTICLE ZOO (CANDY SHOP?) Michael S. Turner

THE EVAPORATION OF STRANGE MATTER IN THE EARLY UNIVERSE Charles Alcock and Edward Farhi

DETECTING COLD DARK MATTER CANDIDATES

A. K. Drukier, K. Freese and D. N. Spergel

CONSTRAINTS ON DARK MATTER DENSITY AND AXION MASS FROM THE LARGE-SCALE STRUCTURE OF SPACETIME

P. S. Joshi and B. Datta

BARYOGENESIS IN THE INFLATIONARY UNIVERSE

Hideo Kodama, Katsuhiko Sato and Nobuaki Sato

COSMOLOGICAL CONSEQUENCES OF AN UNSTABLE HEAVY NEUTRINO

T. Padmanabhan and M. M. Vasanthi

PROSPECTS FOR AXION DETECTION John Moody

THE MISSING MASS AND THE SOLAR NEUTRINO PROBLEM

David Spergel

UNSTABLE DARK MATTER AND GALAXY FORMATION

Yasushi Suto, Hideo Kodama and Katsuhiko Sato

DO BARYON STRUCTURES SURVIVE AFTER THE DECAY OF UNSTABLE PARTICLES? Yasushi Suto and Masafumi Noguchi 
* CONSTRAINTS ON DARK MATTER FROM PRIMORDIAL NUCLEOSYNTHESIS Jean Audouze

POSTER DISCUSSION

C. Norman (Chairman)

525

* CONFERENCE SUMMARY James E. Gunn

* A HISTORICAL PERSPETIVE ON DARK MATTER Scott Tremaine $\quad 547$

GENERAL DISCUSSION J. Peebles and S. Tremaine (Chairmen)

INDICES

INDEX OF NAMES

INDEX OF OBJECTS

582

INDEX OF SUBJECTS

585 